\title{
Chronic Thromboembolic Pulmonary Hypertension (CTEPH) - Potential Role of Multidetector-Row CT (MD-CT) and MR Imaging in the Diagnosis and Differential Diagnosis of the Disease ${ }^{1}$
}

\author{
Die chronisch-thromboembolische pulmonale Hypertonie (CTEPH) - \\ potenzieller Stellenwert von Mehrschicht-CT und MRT in Diagnostik \\ und Differentialdiagnostik der Erkrankung
}

Authors

Affiliations
G. Wirth ${ }^{1}$, K. Brüggemann ${ }^{1}$, T. Bostel ${ }^{1}$, E. Mayer ${ }^{2}$, C. Düber ${ }^{1}$, K. F. Kreitner ${ }^{1}$

Department of Radiology, Universitätsmedizin Mainz

2 Department of Thoracic Surgery, Kerckhoff Hospital, Bad Nauheim
Key words

- chronic thromboembolic pulmonary hypertension

- ECG-gated MD-CTPA

- MR imaging received $\quad 16.12 .2013$

accepted 21.3.2014

\section{Bibliography}

Dol http://dx.doi.org/ 10.1055/s-0034-1366425

Published online: 22.4.2014

Fortschr Röntgenstr 2014; 186:

751-761 @ Georg Thieme

Verlag KG Stuttgart · New York . ISSN 1438-9029

\section{Correspondence}

Prof. K. F. Kreitner

Department of Radiology,

Universitätsmedizin Mainz

Langenbeckstr. 1

55131 Mainz

Germany

Tel.: ++ 49/6131/174160

Fax: ++49/6131/17 6633

karl-friedrich.kreitner@

unimedizin-mainz.de

\section{Zusammenfassung}

$\nabla$

Die chronisch-thromboembolische pulmonale Hypertonie (CTEPH) kann als pulmonalarterielle Hypertonie (mittlerer pulmonalarterieller Ruhedruck $>25 \mathrm{~mm} \mathrm{Hg}$, bestimmt im Rahmen einer Rechtsherzkatheteruntersuchung) mit persistierenden Perfusionsdefekten nach einer einmaligen oder wiederholten Lungenembolie definiert werden. Es handelt sich um eine seltene, aber eher unterdiagnostizierte Erkrankung, deren Inzidenz zwischen 0,5 und 3,8\% nach einer akuten, und bis zu $10 \%$ nach wiederholten Lungenembolien geschätzt wird. Die CTEPH ist die einzige chirurgisch therapierbare Form einer pulmonalen Hypertonie; durch eine erfolgreiche Operation kommt es zur Normalisierung der pulmonalen Hämodynamik und der körperlichen Belastbarkeit. Die Herausforderungen für die Bildgebung bei Patienten mit vermuteter CTEPH sind: hohe diagnostische Genauigkeit bezüglich dem Nachweis einer CTEPH und ihrer differentialdiagnostischen Abgrenzung, Erkennung chirurgisch therapierbarer Patienten, sichere Bestimmung der pulmonalen Hämodynamik (mittlerer pulmonalarterieller Druck und Lungengefäßwiderstand) und Eignung zur Therapieverlaufskontrolle. Diese Übersicht versucht, die potenzielle Rolle der EKG-getriggerten Mehrschicht-CT und der MRT in der Diagnostik der CTEPH zu beleuchten, und fasst die bis dahin erzielten Resultate zusammen. Allgemein zeichnen sich Vorteile für die MS-CT hinsichtlich der Detektion vaskulärer und parenchymatöser Veränderungen ab; mit EKG-Triggerung ermöglicht sie auch eine Beurteilung der kardialen Strukturen. Die Implementierung der Dual-Energy-Technik ermöglicht ein Jod-Mapping des Lungenparenchyms und damit eine Beurteilung der Lungenperfusion. Die MRT gilt nach wie vor als Referenzverfahren für die Beurteilung von Herzfunktion und Lungenperfusion. Neuere Entwicklungen zeigen, dass das Verfahren auch eine Abschätzung der

\section{Abstract \\ $\nabla$}

Chronic thromboembolic pulmonary hypertension (CTEPH) can be defined as pulmonary hypertension (resting mean pulmonary arterial pressure of $25 \mathrm{~mm} \mathrm{Hg}$ or more determined at right heart catheterization) with persistent pulmonary perfusion defects. It is a rare, but underdiagnosed disease with estimated incidences ranging from $0.5 \%$ to $3.8 \%$ of patients after an acute pulmonary embolism (PE), and in up to $10 \%$ of those with a history of recurrent PE. CTEPH is the only form of pulmonary hypertension that can be surgically treated leading to normalization of pulmonary hemodynamics and exercise capacity in the vast majority of patients. The challenges for imaging in patients with suspected CTEPH are fourfold: the imaging modality should have a high diagnostic accuracy with regard to the presence of CTEPH and allow for differential diagnosis. It should enable detection of patients suitable for PEA with great certainty, and allow for quantification of $\mathrm{PH}$ by measuring pulmonary hemodynamics (mPAP and PVR), and finally, it can be used for therapy monitoring. This overview tries to elucidate the potential role of ECG-gated multidetector CT pulmonary angiography (MD-CTPA) and MR imaging, and summarizes the most important results that have been achieved so far. Generally speaking, ECG-gated MD-CTPA is superior to MR in the assessment of parenchymal and vascular pathologies of the lung, and allows for the assessment of cardiac structures. The implementation of iodine maps as a surrogate for lung perfusion enables functional assessment of lung perfusion by CT. MR imaging is the reference standard for the assessment of right heart function and lung perfu-

\footnotetext{
${ }^{1}$ dedicated to Prof. Hans Schild on the occasion of his $60^{\text {th }}$ anniversary and one of my most important teachers of radiology. K-FK
} 
pulmonalen Hämodynamik ermöglicht. Aktuell können MS-CT und MRT als komplementäre Untersuchungsverfahren angesehen werden, die umfassende Informationen bei Patienten mit vermuteter CTEPH ermöglichen. sion, the latter delineating typical wedge-shaped perfusion defects in patients with CTEPH. New developments show that with MR techniques, an estimation of hemodynamic parameters like mean pulmonary arterial pressure and pulmonary vascular resistance will be possible. CT and MR imaging should be considered as complementary investigations providing comprehensive information in patients with CTEPH.

Citation Format:

- Wirth G, Brüggemann K, Bostel T et al. Chronic Thromboembolic Pulmonary Hypertension (CTEPH) - Potential Role of Multidetector-Row CT (MD-CT) and MR Imaging in the Diagnosis and Differential Diagnosis of the Disease. Fortschr Röntgenstr 2014; 186: 751-761

\section{Introduction \\ $\nabla$}

Chronic thromboembolic pulmonary hypertension (CTEPH) is defined as pulmonary hypertension (resting mean pulmonary arterial pressure of $25 \mathrm{~mm} \mathrm{Hg}$ or more determined at right heart catheterization) with persistent pulmonary perfusion defects after a single or recurrent pulmonary embolism [1-3]. It is a rare disease whose incidence is not precisely known. Estimates have ranged from $0.5 \%$ to $3.8 \%$ of patients after an acute pulmonary embolism (PE), and in up to $10 \%$ of those with a history of recurrent PE [4-7].

For reasons still not known, pulmonary emboli in patients with CTEPH do not resolve completely after an episode of acute thromboembolism. Instead, they follow an aberrant path of organization and recanalization leading to characteristic abnormalities such as intraluminal webs and bands, pouch-like endings of arteries, irregularities of the arterial wall, stenotic lesions and complete occlusions [8-10]. This aberrant path of obstruction and reopening occurs in repeated cycles over many years. Some data suggest that in situ thrombosis may play a role in the development of chronic thromboembolic pulmonary hypertension. Additionally, small-vessel arteriopathy, similar to that seen in other forms of pulmonary arterial hypertension (PAH), seems to develop in most CTEPH patients $[10,11]$. This is supported by several observations: (1) progression of pulmonary hypertension typically occurs in the absence of recurrent pulmonary embolic events or in situ pulmonary artery thrombosis; (2) there is a poor correlation between the extent of central vessel occlusion and the degree of pulmonary hypertension: this observation suggests that a component of the increased pulmonary vascular resistance results from the unobstructed, distal vascular bed; and (3) histopathology demonstrates hypertensive arteriopathic changes in the resistance vessels of lung regions both involved and uninvolved in proximal vessel-organized thromboembolic disease.

The disease is characterized by a symptom-free interval which is called the "honeymoon period" [8]. However, due to progressive obstruction of the pulmonary arterial bed, patients develop various degrees of pulmonary hypertension ( $\mathrm{PH}$ ) and progressive right ventricular (RV) failure, depending on the extent of the obstruction in the proximal pulmonary arteries and on the development of progressive secondary arteriopathy in small pre-capillary pulmonary vessels of patent distal pulmonary arteries [11]. These findings result in an elevated mean pulmonary artery pressure [(mPAP), greater than $25 \mathrm{mmHg}$, deterioration of right heart function and exercise capacity and poor prognosis if left untreated $[2,8,11]$.
Surgical pulmonary endarterectomy (PEA) is considered to be the only curative treatment for CTEPH $[11,12]$. PEA significantly reduces the pulmonary vascular pressures and resistances. Results from an international prospective registry yielded an in-hospital mortality of about $5 \%$, and a documented 1-year mortality of $7 \%$. Furthermore, PEA has a high long-term survival rate of $84 \%$ [12]. Surgical operability is clearly based on a center-specific assessment that is subject to large center-to-center variations. Basically, surgical operability is given if the organized thrombi are not located distal to the lobar arteries or to the origin of the segmental arteries in order to develop a safe dissection plane for endarterectomy.

According to the most recent guidelines on pulmonary hypertension, after a positive V/Q scan for CTEPH, invasive pulmonary angiography and MD-CT can be used for detailed work-up of the pulmonary arteries [13-16]. Here, CT angiography gets a class I level $\mathrm{C}$ recommendation meaning that there is evidence and/or general agreement that CTA is beneficial and useful in the diagnosis of CTEPH. On the other hand, in recent recommendations on the diagnosis and treatment of CTEPH, it is always pointed out that a negative $\mathrm{CT}$ angiogram does not rule out surgically treatable forms of CTEPH, and that in these cases a catheter angiography of the pulmonary arteries should be performed [17]. MR imaging is still regarded as an outsider when it comes to imaging strategies in patients with pulmonary hypertension (PH), and actually, there are no general recommendations for its use in the diagnostic work-up of patients with CTEPH $[14,16]$. The challenges for imaging in patients with suspected CTEPH are fourfold: the imaging modality should have a high diagnostic accuracy with regard to the presence of CTEPH and allow for differential diagnosis. It should enable detection of patients suitable for PEA with great certainty. Furthermore, it should allow for the quantification of PH by measuring pulmonary hemodynamics (mPAP and PVR), and finally, it can be used for therapy monitoring. Thus, the purpose of this review is to describe and discuss recent developments of multidetector-row CT (MD-CT) and MR imaging techniques with special regard to their potential in the diagnosis and management of patients with CTEPH.

\section{Assessment of Pulmonary Vasculature $\nabla$} Macrocirculation

Contrast-enhanced MD-CT and contrast-enhanced MR angiography (ce-MRA) allow for the assessment of the pulmonary arteries down to the segmental/subsegmental level $[18,19]$. Specific findings of CTEPH besides the dilatation of the central pulmonary ar- 
teries are: the detection of organized wall-adherent fibrotic material, intraluminal webs and bands, vessel wall irregularities, abrupt vessel cut-offs, complete vessel occlusions and abnormal proximal-to-distal tapering of the vessels ( $\mathbf{F i g . 1 a - c , ~ 2 ) ~ [ 2 0 , 2 1 ] . ~}$ Kreitner et al. [22] showed in a study on 34 patients with CTEPH that - compared with selective DSA - ce-MRA detected typical CTEPH-related vascular changes in all patients and displayed all patent vessel segments down to the level of segmental arteries
(533/533 vessel segments). For subsegmental arteries, however, DSA significantly detected more patent vessel segments than MRA (733 versus 681). In all patients, ce-MRA correctly displayed the most proximal extent of wall-adherent thromboembolic material compared with the beginning of the dissection procedure during PEA.

However, 64-slice and beyond MD-CT angiography of the pulmonary arteries (MD-CTPA) offer advantages over contrast-en-
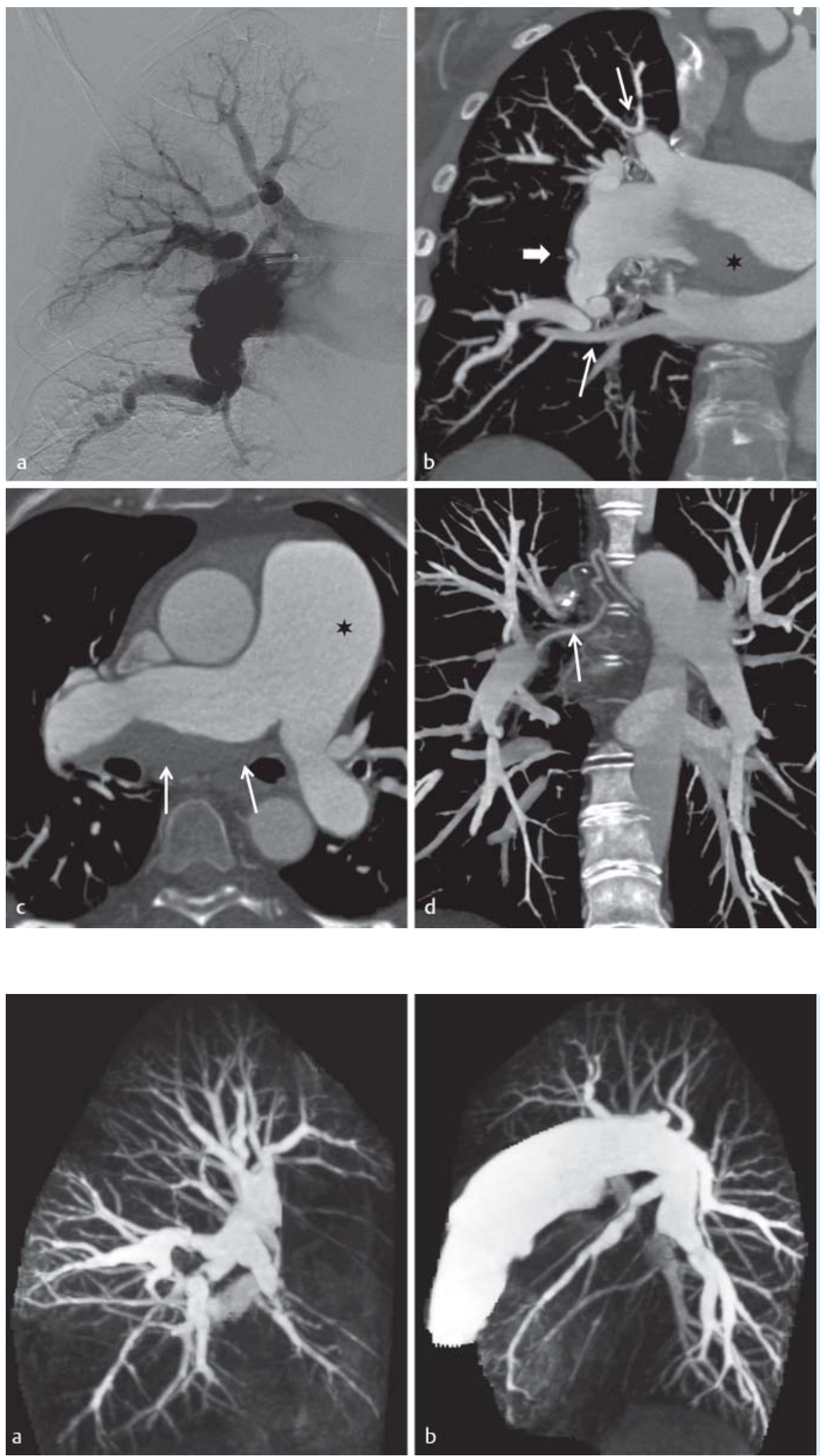

Fig. 1 Vascular findings in a patient with technically operable CTEPH. a Selective DSA of the right pulmonary artery. b Corresponding coronal reformation (subvolume MIP) of an ECG-triggered MDCTPA data set. The CT data set $\mathbf{b}$ better demonstrates the proximal extent of the central wall-adherent thromboemebolic material $\left({ }^{*}\right)$, the typical webs and bands of CTEPH $(\rightarrow$ ), and abrupt vessel cut-offs due to vessel occlusion $(\Rightarrow)$. c Axial image on the level of the main pulmonary artery showing the beginning of the adherent thromboembolic material in the proximal right pulmonary artery $(\rightarrow)$. Dilatation of the main pulmonary artery due to pulmonary hypertension $\left({ }^{*}\right)$. $\mathbf{d}$ Coronal reformation (subvolume-MIP) through the mediastinum shows hypertrophied bronchial artery $(\rightarrow)$.

Abb.1 Gefäßbefunde bei einem Patienten mit operabler CTEPH. a Selektive DSA der rechten Lungenarterie. Korrespondierende koronare Reformatierung (subvolume-MIP) eines EKG-getriggerten MD-CTPA-Datensatzes. b Der CT-Datensatz zeigt besser die proximale Ausdehnung des zentralen thromboembolischen Materials ( $\left.{ }^{*}\right)$, das typische Strickleitmuster der CTEPH $(\rightarrow)$ und abrupt Gefäßabbrüche bedingt durch Gefäßverschlüsse $(\Rightarrow)$. c Die axiale Aufnahme in Höhe des Truncus pulmonalis zeigt den Beginn des wandadhärenten thromboembolischen Materials in der proximalen rechten Pulmonalarterie $(\rightarrow)$. Dilatation des Truncus pulmonalis bedingt durch die pulmonale Hypertonie $\left({ }^{*}\right)$. d Nachweis einer hypertrophierten Bronchialarterie (koronare "subvolume-MIP") $(\rightarrow)$.

Fig. 2 Sagittal data sets of right and left pulmonary arteries. MIP reconstructions of preoperative ce-MRA (TR/TE $=3.34 / 1.24 \mathrm{msec}$; flip angle $=25^{\circ}$, iPAT-factor $=2$, GRAPPA algorithm), acquisition time $=13 \mathrm{sec}, 8 \mathrm{ml}$ of gadobutrol. Complete coverage of the pulmonary arterial vasculature.

Abb. 2 a, b Sagittale Maximum-Intensitäts-Projektionen (MIPs) einer präoperativ durchgeführten, kontrastverstärkten MRA der Lungenstrombahn bds. $\left(T R / T E=3.34 / 1.24 \mathrm{~ms}\right.$; Flipwinkel $=25^{\circ}$, iPATFaktor $=2$, GRAPPA Algorithmus), Aufnahmedauer $=13 \mathrm{sec}, 8 \mathrm{ml}$ Gadobutrol. Komplette Abdeckung der Lungenstrombahn bds. 

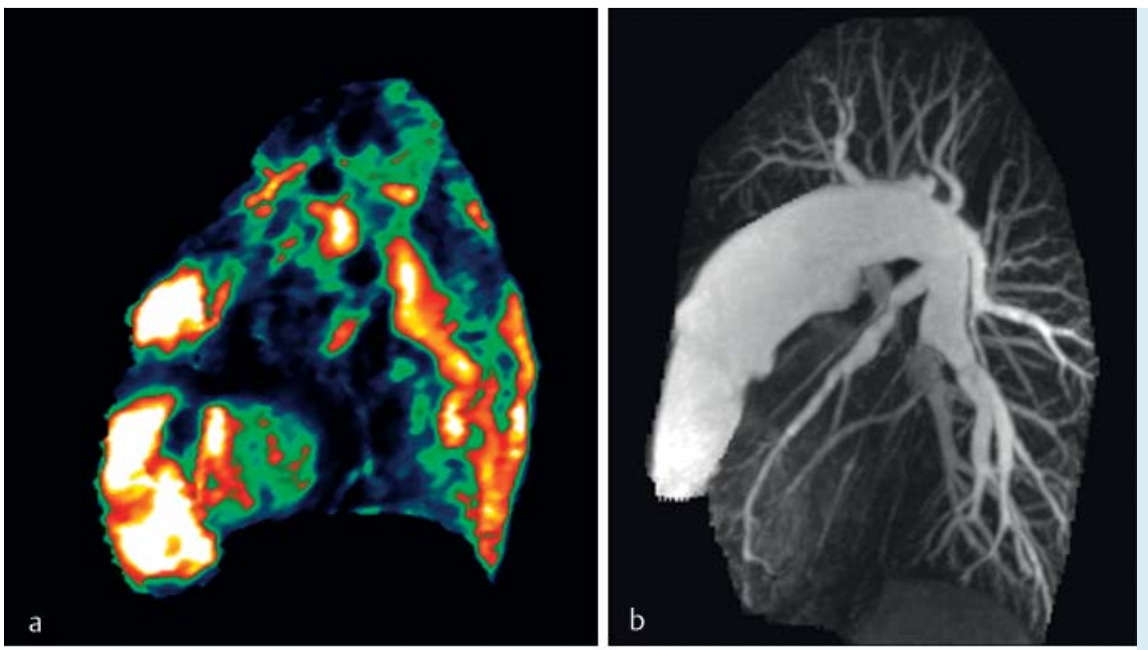

Fig.3 Quantitative pulmonary perfusion imaging: a, c Sagittal parameter maps of pulmonary blood flow in the left and right lungs reveal typical wedgeshaped perfusion defects in both lungs with reduced regional pulmonary blood flow.

Abb.3 Quantitative Lungenperfusionsbildgebung: a, c Die sagittalen Parameterkarten des pulmonalen Blutflusses in der linken und rechten Lungen zeigen keilförmige Perfusionsdefekte beidseits mit reduziertem regionalem Blutfluss.
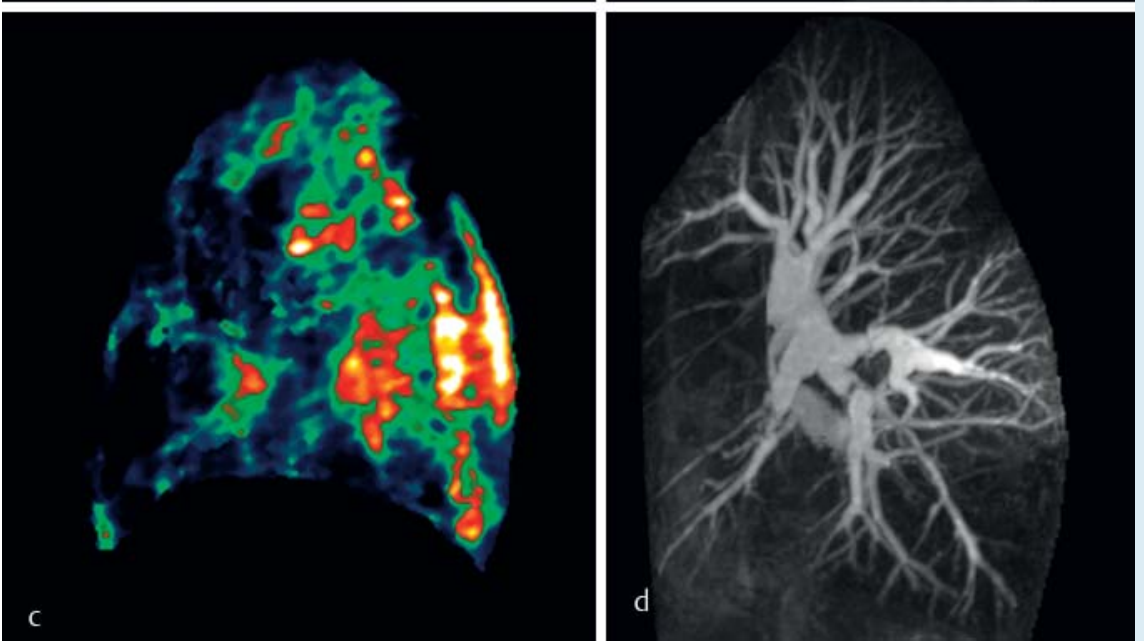

hanced MRA (ce-MRA) because they enable imaging with improved spatial and temporal resolution, shorter scanning times and breath-holds [18-20]. This was confirmed in a retrospective study on 53 patients with CTEPH patients and 36 controls, where ce-MRA had an overall sensitivity of $98 \%$ and a specificity of $94 \%$ for diagnosing the disease with MD-CTPA as the reference standard [23]. In a recent study on 24 patients with suspected CTEPH, it could be shown that retrospectively ECG-gated MD-CTPA was superior to ce-MRA especially for the assessment of the segmental and subsegmental arteries [24]. In this study, MD-CTPA even outperformed selective DSA of the pulmonary arteries in the display of segmental and subsegmental arteries. Also, the proximal extent of the organized thromboembolic material was better delineated by MD-CTPA. In further studies on 27 and 44 CTEPH patients with pulmonary DSA as the reference standard, the sensitivity and specificity of MD-CTPA in detecting thromboembolic findings were $97.0-98.3 \%$ and $94.8-97.1 \%$, respectively, at the main/lobar level and $85.8-94.1 \%$ and $92.9-94.6 \%$, respectively, at the segmental level $[25,26]$.

In a recent study from He et al., MD-CTPA proved to be non-inferior to $\mathrm{V} / \mathrm{Q}$ scanning in diagnosing CTEPH using selective angiography as the reference standard [27].

However, it remains to be determined whether a negative ECGgated MD-CTPA scan precludes a surgically assessable form of CTEPH in all cases $[17,28,29]$ and to what extent MD-CTPA and ce-MRA can distinguish between different forms of pulmonary hypertension [19-30]. Nikolaou et al. in their study on 29 pa- tients with either CTEPH or pulmonary arterial hypertension (PAH) found that based on occluding vascular findings alone, ceMRA enabled correct differentiation between PAH and CTEPH in 24 of 29 patients (83\%) [31].

MD-CTPA and ce-MRA enable the detection of dilated systemic, especially bronchial arteries: flow through these vessels increases in patients with CTEPH because of the obstructions in the pulmonary arteries ( $\bullet$ Fig. $\mathbf{1}$ d). There may be significant systemic to pulmonary shunting, as systemic artery circulation in these cases not only supports the lung parenchyma, but also participates in blood oxygenation [32, 33]. However, the detection of dilated systemic arteries is not a specific sign in patients with CTEPH as it may also be present in other forms of $\mathrm{PH}$.

\section{Microcirculation}

The direct visualization of the most peripheral vascular territories is not possible either by CT or MR imaging. However, MR perfusion techniques allow for the assessment of lung tissue perfusion. Contrast-based perfusion MR is usually performed in combination with ultra-fast $3 \mathrm{D}$ MRA: with the use of parallel imaging techniques, acquisition of time-resolved ce-MRA with reduced spatial resolution is possible with a temporal resolution of $1 \mathrm{~s}$ covering the whole lung volume [34]. Thus, MR perfusion techniques provide insights into regional pulmonary perfusion by tracking the dynamic passage of a contrast bolus: they allow for the differentiation of patients with CTEPH from patients with $\mathrm{PAH}$ : vascular obstructions in CTEPH lead to typical wedge- 

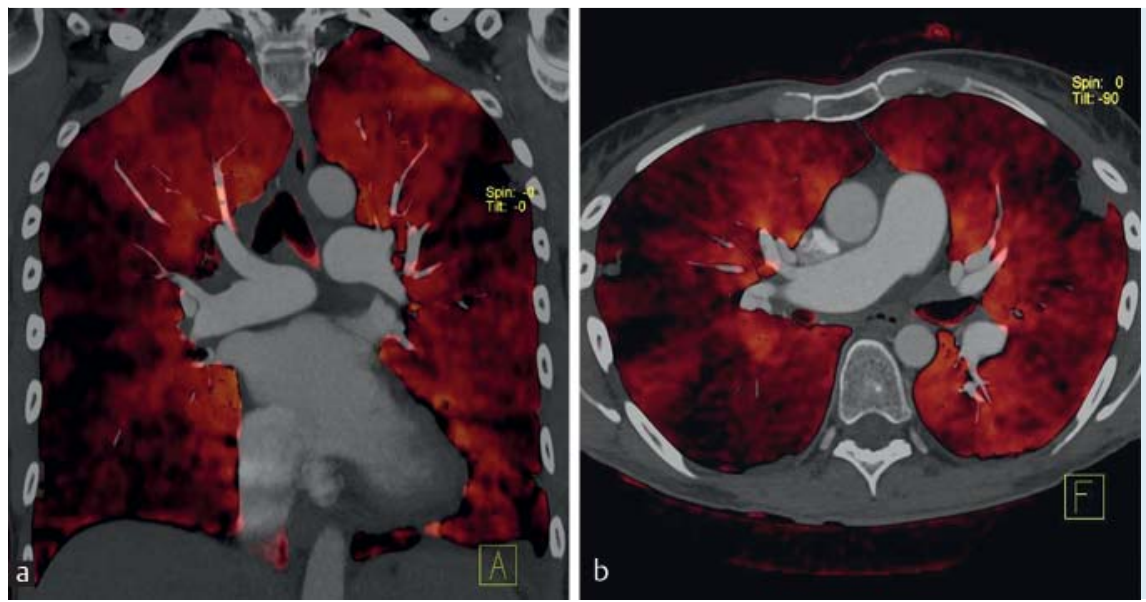

Fig. 4 a, b lodine maps from dual-energy CT in a patient with CTEPH demonstrating wedge-shaped perfusion defects in coronal and axial plane. Courtesy of Dr. Thorsten Johnson, Department of Radiology, University Hospital Großhadern, Munich, Germany.

Abb. 4 a, b lod-Parameterkarten in axialer und koronaler Schnittführung einer Dual-Energy CT-Untersuchung eines CTEPH-Patienten mit Nachweis von keilförmigen Perfusionsdefekten. Courtesy: Prof. Dr. Thorsten Johnson, Institut für klinische Radiologie, Klinikum der Universität München, Campus Großhadern.

shaped perfusion defects, while in PAH the perfusion is overall reduced and inhomogeneous [35]. Absolute quantification of perfusion enables the determination of pulmonary blood flow (PBF), blood volume (PBV) and mean transit time (MTT). The wedge-shaped perfusion defects in CTEPH patients clearly delineate regionally reduced PBF and PBV together with a prolonged MTT that correspond with large obstructions in proximally located pulmonary arteries ( $\bullet$ Fig. 3). Furthermore, the technique seems to detect perfusion deficits even in those cases where ce-MRA displays patent subsegmental vessels [36]. In a large single-center study of a national referral center on 132 consecutive patients with $\mathrm{PH}$, a qualitative analysis of contrast-enhanced MR lung perfusion revealed a sensitivity of $97 \%$ and a specificity of $92 \%$ in the detection of CTEPH patients. Its performance was comparable to that of perfusion scintigraphy, and it did not miss any patients with a surgically treatable form of CTEPH [37].

The introduction of dual-source, dual-energy CT (DE-CT) allows generation not only of cross-sectional images. Based on a threedimensional decomposition algorithm, the technique enables iodine contrast-material extraction in tissues without the need for complex image registration. These iodine maps may reflect lung tissue perfusion. First studies in patients with CTEPH revealed that the technique allows for the depiction of perfusion defects beyond chronically occluded vessels. These defects closely mirrored the mosaic perfusion attenuation pattern in one study [38] ( $\odot$ Fig. 4). A further study showed that perfusion defects were only seen in patients with severe obstruction of the pulmonary arteries. The authors concluded that despite the presence of enlarged systemic arteries in these cases, normal parenchymal reperfusion is not reached via this collateral supply [39]. DE-CT identified all patients with CTEPH among 40 consecutive patients with proven pulmonary hypertension in comparison with $\mathrm{V} / \mathrm{Q}$ scintigraphy [40]. Furthermore, the technique can be used for automated quantification of pulmonary perfused blood volume (PBV) in patients with CTEPH. These PBV values correlated inversely with systolic and mean pulmonary arterial pressures [41].

\section{Assessment of Lung Parenchyma}

$\nabla$

The parenchymal findings in patients with CTEPH are - though nonspecific - often helpful. One frequent finding of MD-CTPA is peripheral opacities caused by previous parenchymal infarction,

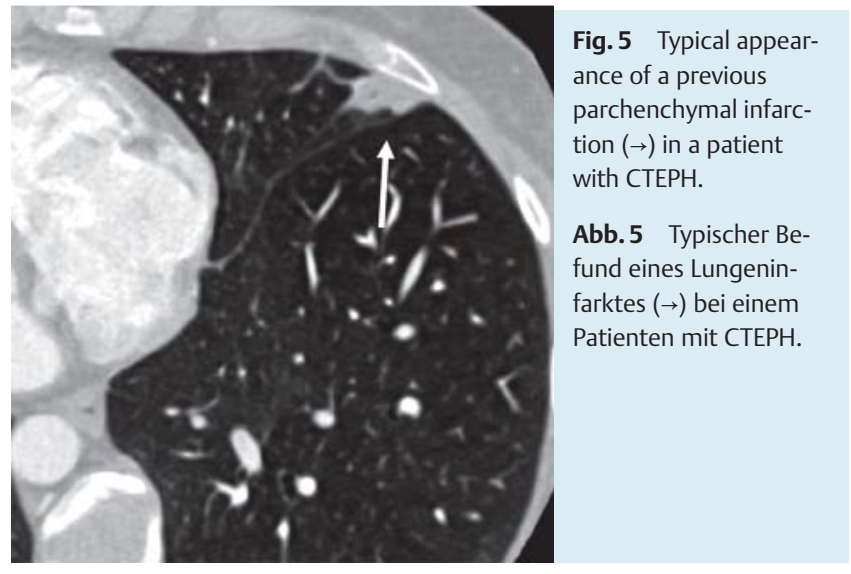

and the other is mosaic lung perfusion ( $\bullet$ Fig. 5, 6). The latter is characterized by sharply demarcated regions of hypoattenuation that is produced by hypoperfusion in lung areas distal to occluded vessels or by small-vessel arteriopathy in non-obstructed lung areas [20,21]. Hyperattenuation on the other hand is the sequelae of a compensatory increase in blood flow to patent pulmonary vessels. Up to now, MR imaging has not played a significant role in the assessment of lung parenchyma in CTEPH patients.

\section{Assessment of Coronary Arteries}

$\nabla$

The introduction of 64-slice MD-CT and beyond scanners enables the superb delineation not only of the pulmonary arteries, but also of the thoracic aorta and coronary arteries in one examination. This approach has been widely used in emergency cases in patients with an acute coronary syndrome displaying unspecific ECG findings and non-significant elevations of biomarkers, known as the triple rule-out approach $[42,43]$. As patients with a surgically assessable form of CTEPH routinely undergo left heart catheterization (LHC) for the exclusion of significant coronary artery disease (CAD), an extension of the ECG-gated MD-CTPA protocol would enable detection of patients without significant CAD, thereby avoiding the need for LHC. Although no larger series are available, first experiences are quite encouraging [44]. 

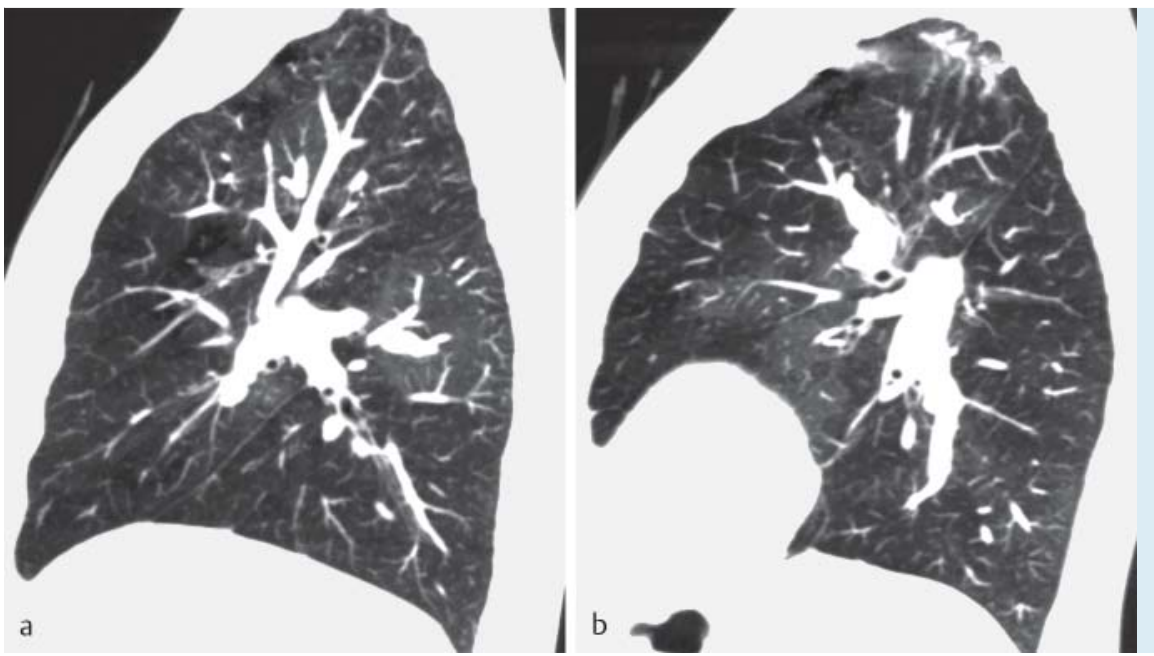

Fig. 6 a, b Typical mosaic perfusion pattern, sagittal MPRs through the right and left lungs.

Abb. 6 a, b Typisches Mosaikperfusionsmuster, sagittale MPRs durch die rechte und linke Lunge.

\section{Assessment of Right Heart Impairment and Pulmonary Arterial Flow \\ $\nabla$}

Cine MR imaging (Cine-MRI) is an accepted reference standard for the assessment of global and regional right (RV) and left (LV) ventricular function and mass. Cine imaging in CTEPH patients typically reveals a hypertrophy and/or dilatation of the right ventricle leading to increased enddiastolic and endsystolic RV volumes (EDV, ESV) with reduced RV ejection fraction $[22,45]$. Compared with healthy volunteers, patients with CTEPH have a significantly increased RV mass. The increasing regurgitation over the tricuspid valve finally leads to an enlarged right atrium. Although there is no substantial impairment of global systolic LV function, the chronic RV pressure overload leads to alterations in LV geometry with flattening or convex bowing of the interventricular septum. This phenomenon can be explained by the interventricular mechanical dyssynchrony which is characteristic for $\mathrm{RV}$ pressure overload. It occurs at the end of RV myocardial shortening, while the left ventricular wall is already in its early diastolic phase. Consequently, the ventricular septum bows to the left, and the RV shortens without ejection. This leads, however, to impaired diastolic filling of the LV which may result in a decreased LV stroke volume and $\operatorname{LV} \operatorname{EF}[45,46]$.

Flow measurements in the main pulmonary artery by phase-contrast MR imaging (PC-MRI) show that in comparison with aortic flow the net forward volume is significantly lower. This difference in flow can be explained by the broncho-systemic shunt volume that is caused by dilation of bronchial or systemic arteries that originate from the aorta. There is also a reduced peak velocity in the pulmonary artery that shows some correlation with the increased pulmonary resistance (PVR) and mean pulmonary arterial pressure (mPAP) $[22,45]$.

Postoperatively, Cine and PC-MRI imaging are well suited to document the reverse right ventricular remodeling which occurs in the majority of patients after successful pulmonary endarterectomy. This reverse remodeling can be documented in the early postoperative period and consists of a significant decrease of RVEDV and ESV accompanied by a significant increase of RV-SV and RV-EF. The change in RV-EF correlates with changes in pulmonary resistance and mean pulmonary arterial pressure [45 - 47]. Compared with age-matched controls, however, RV function remains below normal values 6 months after surgery. The decrease in ventricular volumes goes along with a reduction of right ventricular mass, again not reaching normal values compared with healthy controls, indicating that MPAP and PVR do not return to normal values in all patients. Early after PEA, a significant reduction in the abnormal position of the ventricular septum can be noted and remains constant during further follow-up. This change in septal bowing also correlates with the hemodynamic improvement after PEA ( $\bullet$ Fig. 7 ). The reduction of end-systolic wall stress in RV after successful PEA leads to a synchronization of interventricular dyssynchrony by resynchronization of RV and LV peak strains. The improvement in RV function also has some positive effects on LV function: the normalization of septal bowing of the interventicular septum improves diastolic filling of the LV leading to increased stroke volumes and increased net forward flow volumes in the ascending aorta [46-48].

PEA also has a beneficial effect on flow patterns and velocities in the pulmonary trunk. However, for the side branches, a dichotomous effect is found with a sustained improvement for the right pulmonary artery and nearly no improvement for the left pulmonary artery. There may be different explanations for that finding, however. When comparing with postoperative MR angiograms, there were significantly more re-opened segmental vessels in the right lung compared with the left lung [22, 45 - 47].

\section{Assessment of Pulmonary Hemodynamics: Noninva- sive Estimation of MPAP and PVR $\nabla$}

There have been many reports that show significant relationships between $\mathrm{CT}$ and MR-related metrics and pulmonary hemodynamics [49]. Even for ECG-gated MD-CTPA, significant correlations could be found in patients with CTEPH between the curvature of the interventricular septum and the mean and systolic pulmonary arterial pressures as determined by RHC [26]. There was also a correlation between the Cobb angle which is defined as the angle between the interventricular septum and the line between the sternal midpoint and thoracic vertebral spinous process measured during diastole with PVR $[41,50]$. However, the results of these studies were not validated in prospective cohort studies.

Actually, there are three published MR-based approaches for noninvasive assessment of MPAP and/or PVR ( $\bullet$ Table 1). Garcia-Alvarez et al. presented an MR-based method for the assessment of pulmonary vascular resistance using a derivation and validation 

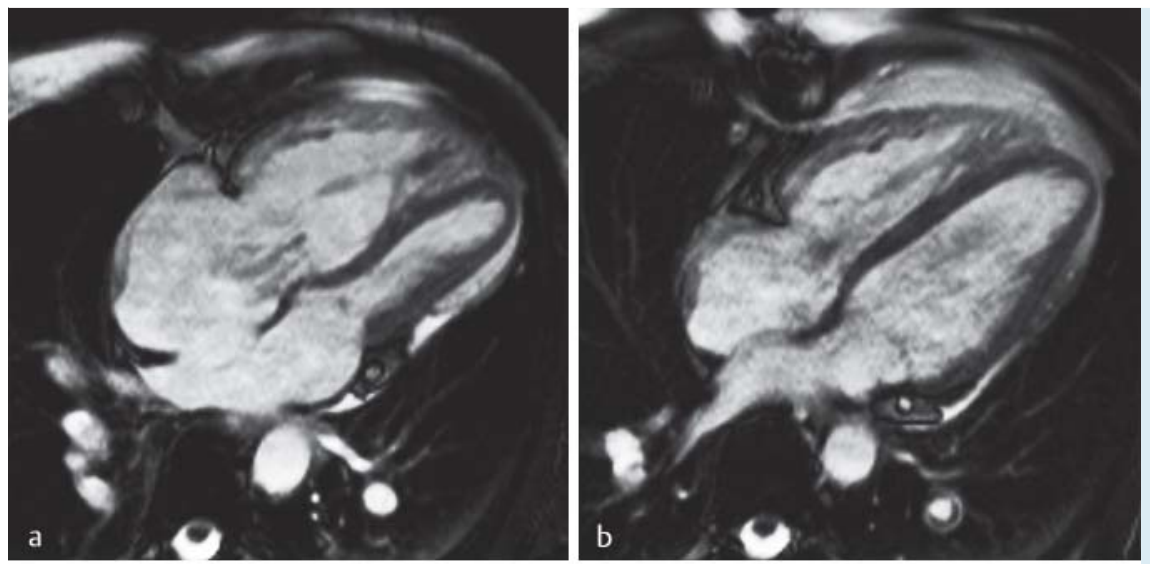

Fig. 7 Reverse remodeling of the right ventricle 2 weeks after successful pulmonary endarterectomy. a, b Preoperative Cine images, 4-chamber and short-axis views. c, d Postoperative Cine image, 4chamber and short-axis views.

Abb. 7 Reverses Remodeling des rechten Ventrikels 2 Wochen nach erfolgreicher pulmonaler Endarterektomie. a, b Präoperative Cine-Bildgebung im 4-Kammerblick und in der sagittalen Kurzachse. c, $\mathbf{d}$ postoperative Cine-Bildgebung im 4-Kammerblick und in der sagittalen Kurzachse.
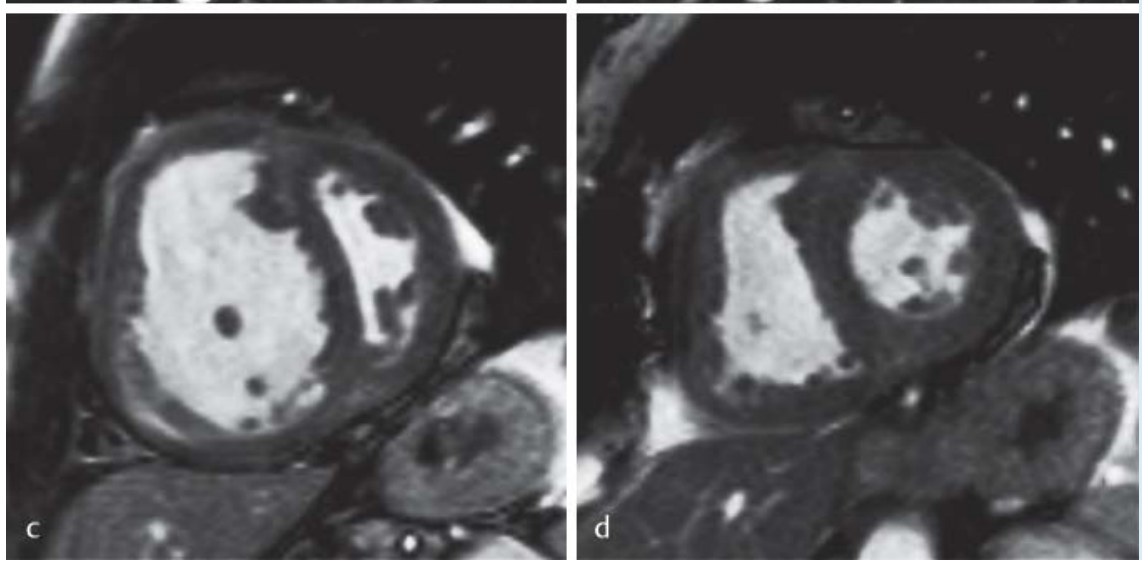

Table 1 Assesment of pulmonary hemodynamics by MR imaging.

\begin{tabular}{|c|c|c|c|}
\hline & $\begin{array}{l}\text { Garcia-Alvarez } \\
\text { et al., } 2011\end{array}$ & $\begin{array}{l}\text { Swift et al., } \\
2013\end{array}$ & $\begin{array}{l}\text { Kreitner et al., } \\
2013\end{array}$ \\
\hline patients & $\begin{array}{l}\text { derivation } \\
\text { cohort: } \\
n=100 \\
\text { validation } \\
\text { cohort: } \\
n=20\end{array}$ & $\begin{array}{l}\text { derivation } \\
\text { cohort: } \\
n=64 \\
\text { validation } \\
\text { cohort: } \\
n=64\end{array}$ & $\begin{array}{l}\mathrm{n}=19 \\
\text { validation } \\
\text { model } \\
\text { invasively } \\
\text { recorded mPAP }\end{array}$ \\
\hline technique & $\begin{array}{l}\text { standard Cine- } \\
\text { and PC-MRI: } \\
\text { nat. log PA } \\
\text { average veloc- } \\
\text { ity and RV-EF }\end{array}$ & $\begin{array}{l}\text { Cine-MRI: } \\
\text { VMI, inter- } \\
\text { ventricular } \\
\text { septal angle; } \\
\text { LA size adjusted } \\
\text { to BSA }\end{array}$ & $\begin{array}{l}\text { PC-MRI: } \\
\text { temporal reso- } \\
\text { lution }=10 \mathrm{~ms} \\
\text { Ata, } \mathrm{MV}, \mathrm{AV} \text {, } \\
\mathrm{dQ} / \mathrm{dt} \text { and } \mathrm{CO}\end{array}$ \\
\hline $\begin{array}{l}\text { mPAP } \\
\text { (limits of } \\
\text { agree- } \\
\text { ment) }\end{array}$ & - & $\begin{array}{l}-15.7- \\
+14.7 \mathrm{mmHg}\end{array}$ & $-7-+6 \mathrm{mmHg}$ \\
\hline $\begin{array}{l}\text { PVR (limits } \\
\text { of agree- } \\
\text { ment) }\end{array}$ & $\begin{array}{l}-482-+395 \\
\text { dyn } \cdot s \cdot \mathrm{cm}^{-5}\end{array}$ & $\begin{array}{l}-408-+368 \\
\text { dyn } \cdot s \cdot \mathrm{cm}^{-5}\end{array}$ & $\begin{array}{l}-237-+138 \\
\text { dyn } \cdot s \cdot \mathrm{cm}^{-5}\end{array}$ \\
\hline
\end{tabular}

Ata $=$ absolute acceleration time, $\mathrm{AV}=$ volume of acceleration, $\mathrm{BSA}=$ body surface area, $\mathrm{CO}=$ cardiac output, $\mathrm{dQ} / \mathrm{dt}=\mathrm{MV}=$ maximum of mean velocities, maximal flow acceleration, $\mathrm{LA}=$ left atrium, $\mathrm{PA}=$ pulmonary artery, nat log = natural logarithm, $\mathrm{VMI}=$ ventricular mass index.

cohort with different forms of pulmonary hypertension [52]. Their statistical model is based on standard cine and phase-contrast sequences. These sequences were acquired in 100 patients with RHC performed on the same day. The model combining natural logtransformed PA average velocity and right ventricular (RV) ejection fraction showed the best statistical performance with invasively measured PVR. With that model, the area under the ROC curve to detect increased PVR was 0.96 for the derivation cohort $(n=80$ patients), and 0.97 ( $n=20$ patients) for the validation cohort. There were no statistical differences in diagnostic accuracy between the different forms of pulmonary hypertension, and the $95 \%$ confidence interval ranged from -6.02 to +4.94 wood units, corresponding to -482 to $+395 \mathrm{dyn} \cdot \mathrm{s} \cdot \mathrm{cm}^{-5}$ in the validation cohort.

Swift et al. in a current study created an MR-based noninvasive composite parametric regression model for the estimation of pulmonary hemodynamics based on CMR examinations of 64 patients that underwent RHC on the same day (derivation cohort) [53]. This regression model could be prospectively validated in 64 patients (validation cohort). For the estimation of MPAP, a numerical linear regression model consisting of a composite index of the ventricular mass index (ratio between RV and LV mass; VMI) and interventricular septal angle correlated well with mPAP in both cohorts with limits of agreement ranging from 15.7 to $14.7 \mathrm{mmHg}$. For estimation of pulmonary capillary wedge pressure (PCWP), the size of the left atrium adjusted for body surface area was used and showed a moderate correlation with invasively measured PCWP. PVR was finally calculated by subtraction of calculated PCWP from calculated mPAP divided by cardiac output as determined by phase-contrast imaging in the pulmonary artery. For estimated PVR, the authors found limits of agreement ranging between -5.1 and +4.6 wood units, which were slightly narrower than those of the validation group in the study of Garcia-Alvarez et al. [52, 53].

Kreitner et al. used a phase-contrast sequence with high temporal resolution in the main pulmonary artery for the assessment of hemodynamics in patients with CTEPH. Reference standards, in- 
vasive catheter-based measurements of mPAP, were simultaneously acquired [54]. Based on MR-derived parameters, a multiple linear regression analysis revealed a maximum achievable model fit of $B=0.902$. There was an encouraging concordance between calculated and directly measured mPAP values $\left(R^{2}=0.89\right)$ with a median intraindividual deviation of $-1 \mathrm{mmHg}$, and agreement limits between -7 and $+6 \mathrm{mmHg}$ ( $\bullet$ Fig. 8). MR-based calculation of pulmonary vascular resistance (PVR) showed an overestimation with a median value of $-112 \mathrm{dyn} \cdot \mathrm{s} \cdot \mathrm{cm}^{-5}$ (i.e., -1.4 wood units), and agreement limits between -237 and 138 dyn.s. $\mathrm{cm}^{-5}$ (i. e., -3.0 and 1.7 wood units) compared with data from same day right heart catheterization. These first results seem to be quite encouraging. However, they have to be validated in a larger patient population.

\section{Differential Diagnosis}

One important differential diagnosis is distinguishing CTEPH from idiopathic pulmonary arterial hypertension (IPAH). The lack of wall-adherent thromboembolic material, a pronounced dilatation of the central pulmonary arteries, a marked decrease in the caliber of the segmental and subsegmental arteries, and the lack of fibrotic obstructions are typical findings in patients with idiopathic pulmonary arterial hypertension ( $\bullet$ Fig. 9). A further specific finding of IPAH is corkscrew-like peripheral pulmonary arteries that represent intimal cellular proliferation and medial hypertrophy as part of the plexogenic arteriopathy [20, 21].

Sometimes acute thromboembolism with extensive right heart impairment may cause difficulties in differentiation from CTEPH. However, acute emboli present as central, intraluminal filling defects. If located in an eccentric position, an acute thromboembolus forms an acute angle with the vessel wall, contrary to the obtuse angle noted in CTEPH. Although right-sided ventricular dilatation and pulmonary infarction can be observed in both entities, hypertrophy of the right ventricle and dilated bronchial arteries are unlikely to be seen in acute thromboembolism [55].

A very important differential diagnosis is primary sarcoma of the pulmonary artery. Though uncommon, its rarity and nonspecific presentation can make it indistinguishable from CTEPH. Features on CT and MR include a solid lobulated mass located in the central pulmonary arteries whose enhancement may be very subtle. In this regard, MR imaging may offer advantages over $\mathrm{CT}$, and it better displays the presence of appositional thrombus formation ( $\bullet$ Fig. 10). Extravascular extension into the surrounding par-

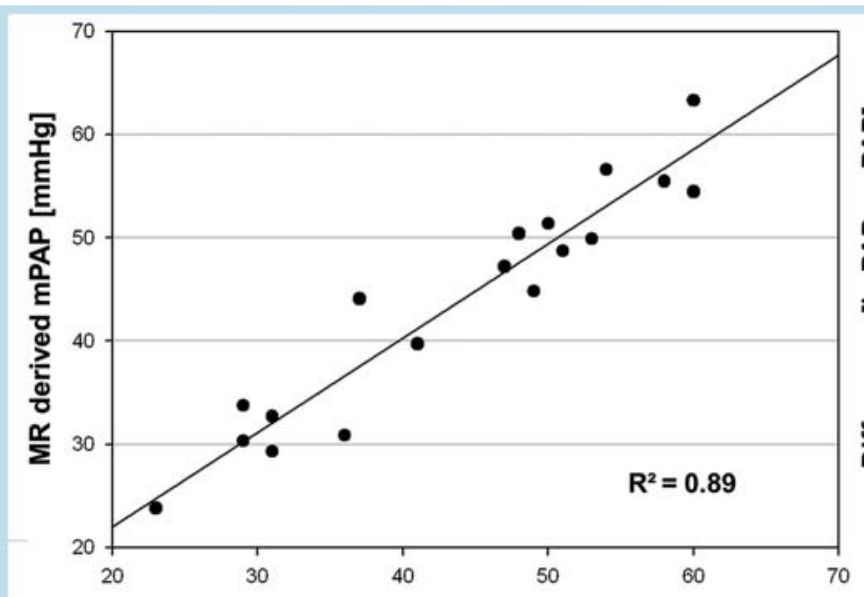

a

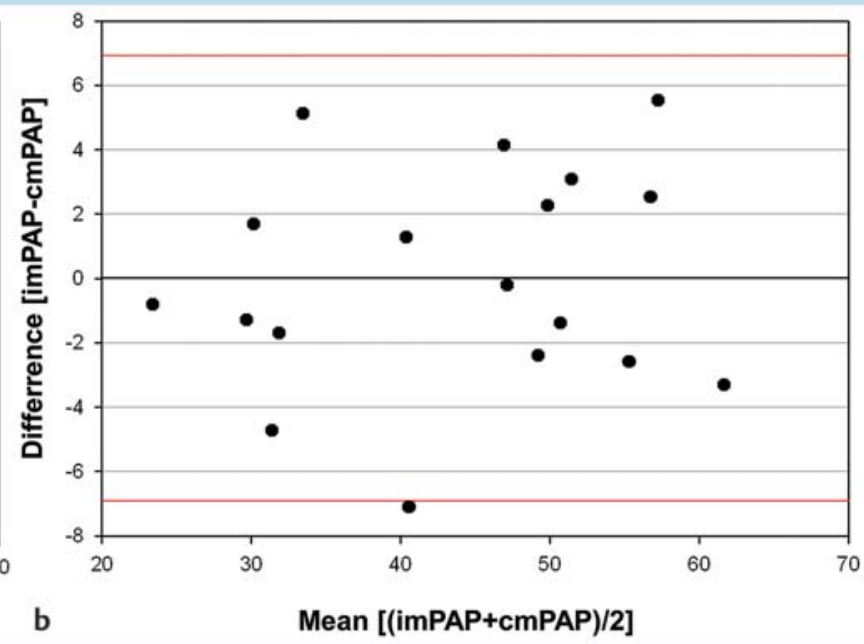

Fig. 8 Correlation between simultaneous and invasively measured mPAP and estimated mPAP by MR-derived parameters a; Bland-Altman-Plot b.

Abb. 8 Korrelation zwischen invasiv simultan gemessenem und anhand von MR-Parametern berechneten mPAP a; Bland-Altman-Plot b.

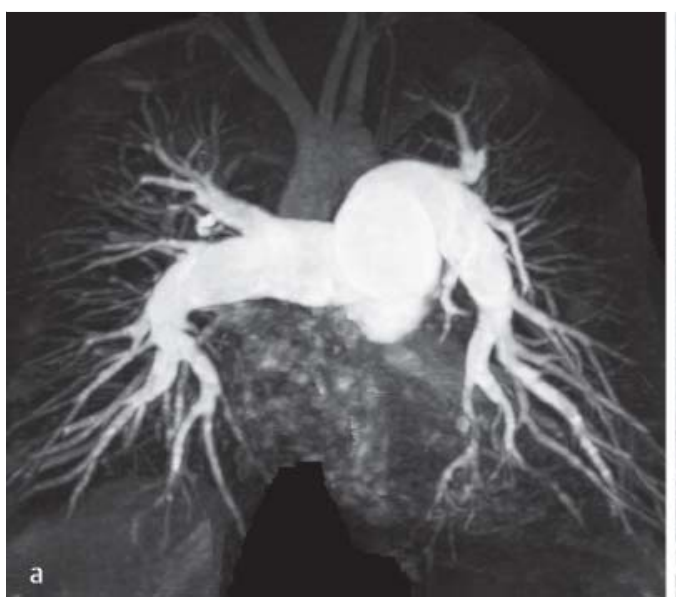

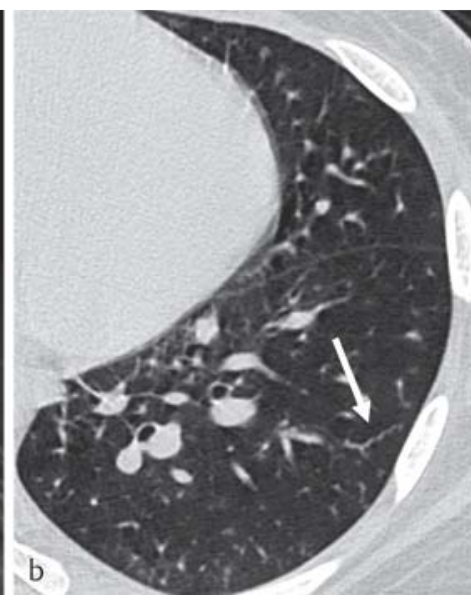

Fig. 9 20-year-old female patient with IPAH before lung transplantation. Contrast-enhanced MRA depicts enlarged central pulmonary arteries and a marked decrease in the caliber of the segmental and subsegmental arteries. There are no intraluminal webs and bands, no abrupt vessel cutoffs a. HRCT shows a lack of fibrosis and typical corkscrew-like peripheral pulmonary arteries $(\rightarrow)$ b.

Abb. 9 20-jährige Patientin mit IPAH vor geplanter Lungentransplantation. Die kontrastverstärkte MRA zeigt erweiterte zentrale Lungenarterien und eine deutliche Kaliberreduktion in der Peripherie. Intraluminale Strickleiter, abrupte Kalibersprünge oder -abbrüche finden sich nicht a. Die HR-CT zeigt keine Lungenfibrose, jedoch typische schraubenzieherartig gewundene periphere Lungenarterien $(\rightarrow) \mathbf{b}$. 

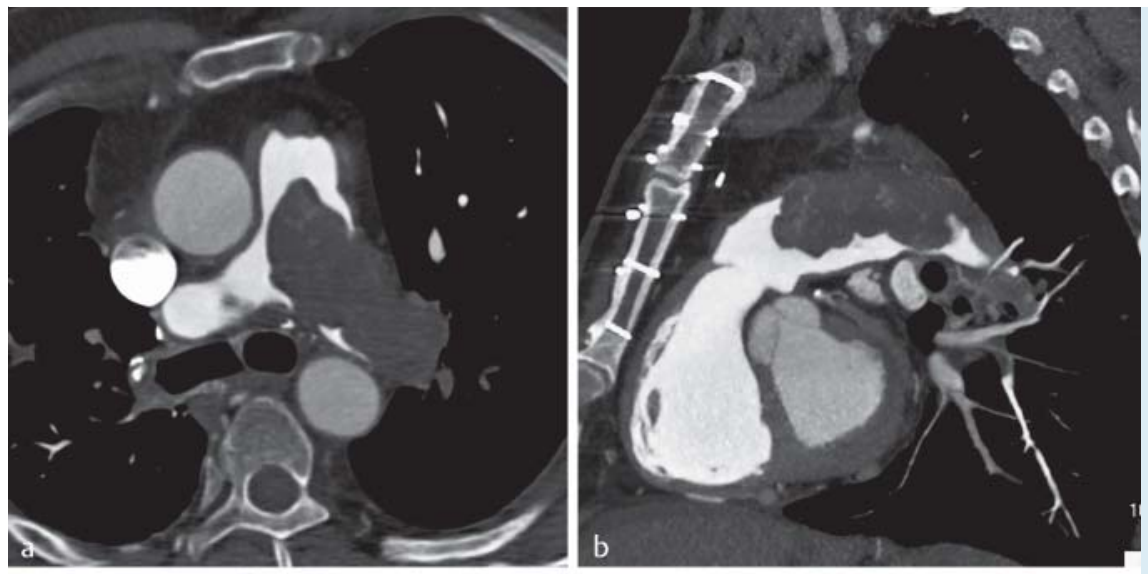

Fig. 10 Recurrent pulmonary artery sarcoma. a, b CT demonstrates a solid lobulated mass located in the central pulmonary arteries whose enhancement is very subtle. $\mathbf{c}, \mathbf{d}$ MR imaging better displays the appositional thrombus formation $(\bigcup)$ in comparison with the enhancing tumor tissue $\mathbf{d}$.

Abb. 10 Rezidiv eines Pulmonalarteriensarkoms. a, b Die CT-Untersuchung dokumentiert eine in den zentralen Lungenarterien links wachsende Raumforderung mit nur diskreter KM-Anreicherung. c, $\mathbf{d}$ Die MR-Bildgebung erlaubt eine bessere Differenzierung zwischen kontrastaufnehmendem Tumor und Appositionsthrombus ( $)$ d.
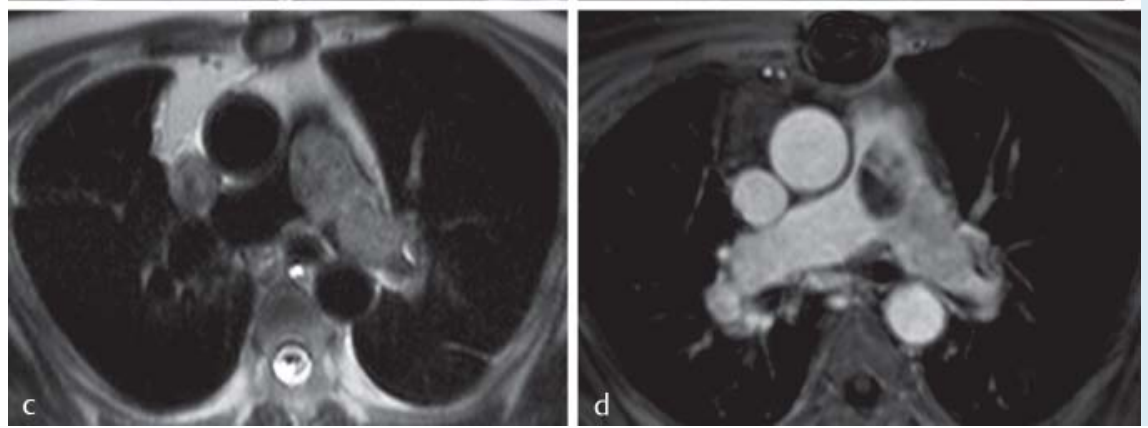

enchyma or mediastinal structures and the presence of distant lung metastases are diagnostic. Furthermore, sarcomas may show an avid uptake of 18F-fluorodeoyglucose on PET-CT scans [56, 57].

Involvement of the pulmonary arteries with the development of pulmonary arterial hypertension has been reported in the course of Takayasu arteriitis, and isolated pulmonary arteriitis is rare [58]. Affected pulmonary arteries may exhibit concentric or eccentric stenosis due to mural thickening followed by normal vessel segments. Systemic vessel involvement and the absence of an intraluminal pulmonary thrombus may aid in finding the correct diagnosis.

\section{Conclusion}

The present review tries to elucidate the potential of ECG-gated MD-CTPA and MR imaging in the assessment of patients with CTEPH as they address many aspects of the disease ( $\bullet$ Table 2 ). However, both imaging modalities have their own specific limitations making it difficult to use either modality ubiquitously. ECGgated MD-CTPA clearly has advantages in the assessment of lung parenchyma and pulmonary vasculature. It is widely available and less expensive than MR imaging. The implementation of iodine mapping with dual-energy CT as a surrogate of lung perfusion will make it an ideal tool for the detection of wedge-shaped perfusion defects in patients with CTEPH and will perhaps replace the need for $\mathrm{V} / \mathrm{Q}$ scanning in these patients. The main limitations for CT include the application of iodinated contrast agents and radiation exposure. However, the latter can be reduced dramatically without compromising diagnostic accuracy by using e.g. step-and shoot techniques or iterative reconstruction algorithms. MR imaging is limited by current contraindications for ferromagnetic items, claustrophobia and a rare, but possible risk of nephrogenic systemic fibrosis after exposure to Gd-
Table 2 Rating of MD-CTPA and MRI in the diagnosis and differential diagnosis of CTEPH.

\begin{tabular}{|c|c|c|}
\hline & ECG-gated MD-CTPA & MR imaging \\
\hline macrocirculation & +++ & $(+)++$ \\
\hline perfusion imaging & $++(+)$ & +++ \\
\hline $\begin{array}{l}\text { assessment of lung } \\
\text { parenchyma }\end{array}$ & +++ & - \\
\hline $\begin{array}{l}\text { assessment of coronary } \\
\text { arteries }\end{array}$ & +++ & + \\
\hline right heart impairment & $++(+)$ & +++ \\
\hline $\begin{array}{l}\text { pulmonary } \\
\text { hemodynamics }\end{array}$ & + & +++ \\
\hline monitoring of therapy & - & +++ \\
\hline
\end{tabular}

based chelates in patients with renal insufficiency. However, it enables precise assessment of cardiac function and vascular parameters, including regional analysis of lung tissue perfusion. Very important is the possibility to noninvasively assess hemodynamic parameters like MPAP and PVR. Future studies should focus on the ability of ECG-gated MD-CTPA in ruling out surgically operable patients. Furthermore, the possibilities of MR imaging in the assessment of pulmonary hemodynamics have to be intensified. Future research will focus on the implementation of temporally resolved $3 \mathrm{D}$ flow measurements with regard to their ability to detect and to assess the degree of pulmonary hypertension and to monitor therapy. Initial results are quite promising $[59,60]$.

ECG-gated MD-CTPA and MR imaging should be considered as complementary investigations, and it can be anticipated that their combined use enables accurate disease classification and therapy planning thereby avoiding the need for further invasive or noninvasive examinations in the vast majority of patients 
with suspected CTEPH. However, appropriate experience and expertise in imaging of these patients remain basic prerequisites.

\section{References}

1 Hythe J. Chronic thromboembolic pulmonary hypertension: a review of current practice. Prog Cardiovasc Dis 2012; 55: 134-143

2 Keogh AM, Mayer E, Benza L et al. Interventional and surgical modalities of treatment in pulmonary hypertension. J Am Coll Cardiol 2009; 54: S67-S77

3 Pepke-Zaba J, Delcroix M, Lang I et al. Chronic thromboembolic pulmonary hypertension (CTEPH). Results from an international prospective registry. Circulation 2011; 124: 1973-1981

4 Becattini C, Agnelli G, Pesavento $R$ et al. Incidence of chronic thromboembolic pulmonary hypertension after a first episode of pulmonary embolism. Chest 2006: 130: 172-175

5 Pengo $V$, Lensing $A W$, Prins $M H$ et al. Incidence of chronic thromboembolic pulmonary hypertension after pulmonary embolism. $\mathrm{N}$ Engl J Med 2004; 350: 2257-2264

6 Klok FA, van Kralingen KW, van Dijk AP et al. Prospective cardiopulmonary screening program to detect chronic thromboembolic pulmonary hypertension in patients after acute pulmonary embolism. Haematologica 2010; 95: 970-975

7 Berghaus TM, Barac M, von Scheidt W et al. Echocardiographic evaluation for pulmonary hypertension after recurrent pulmonary embolism. Thromb Res 2011; 128: e142 - e147

8 Frazier AA, Galvib JR, Franks TJ et al. Pulmonary vasculature: hypertension and infarction. Radiographics 2000; 20: 491-524

9 Darteville P, Fadel E, Mussot S et al. Chronic thromboembolic pulmonary hypertension. Eur Respir J 2004; 23: 637-648

10 Piazza G, Goldhaber SZ. Chronic thromboembolic pulmonary hypertension. N Engl J Med 2011; 364: 351 - 360

11 Simonneau G, Robbins IM, Beghetti M et al. Updated clinical classification of pulmonary hypertension. J Am Coll Cardiol 2009; 54: S43 -S54

12 Mayer E, Jenkins D, Lindner J et al. Surgical management and outcome of patients with chronic thromboembolic pulmonary hypertension: results from an international prospective registry. J Thorac Cardiovasc Surg 2011; 141: $702-710$

13 Jaff MR, McMurtry MS, Archer SL et al. Management of massive and submassive pulmonary embolism, iliofemoral deep vein thrombosis, and chronic thromboembolic pulmonary hypertension. A scientific statement from the American Heart Association. Circulation 2011; 123: $1788-1830$

14 Galié N, Hoeper MM, Humbert M et al. Guidelines for the diagnosis and treatment of pulmonary hypertension. The task force for the diagnosis and treatment of pulmonary hypertension of the Europen Society of Cardiology (ESC) and the European Respiratory Society (ERS), endorsed by the International Society of Heart and Lung Transplantation (ISHLT). Eur Heart J 2009; 30: 2493 - 2537

15 Brown K, Gutierrez AJ, Mohammed T-LH et al. ACR appropriateness criteria ${ }^{\circledR}$ pulmonary hypertension. J Thorac Imaging 2013; 28: W57-W60

16 Kim NH, Delcroix M, Jenkins DP et al. Chronic thromboembolic pulmonary hyptertension. J Am Coll Cardiol 2013; 62: D92 - D99

17 Wilkens H, Lang I, Behr J et al. Chronic thromboembolic pulmonary hypertension (CTEPH): updated recommendations of the Cologne consensus conference 2011. Int J Cardiol 2011; 154S: S54 - S60

18 Pena E, Dennie C, Veinot J et al. Pulmonary hypertension: how the radiologist can help. Radiographics 2012; 32: 9-32

19 Tsai IC, Tsai WL, Wang KY et al. Comprehensive MDCT evaluation of patients with pulmonary hypertension: diagnosing underlying causes with the updated Dana Point 2008 classification. Amer J Roentgenol 2011; 197: W471 -W481

20 Castaner E, Gallarda X, Ballesteros E et al. CT diagnosis of chronic pulmonary thromboembolism. Radiographics 2009; 29: $31-53$

21 Grosse C, Grosse A. CT findings in diseases associated with pulmonary hypertension: a current review. Radiographics 2010; 30: 1753-1777

22 Kreitner KFJ, Ley S, Kauczor HU et al. Chronic thromboembolic pulmonary hypertension: pre-and postoperative assessment with breathhold MR imaging techniques. Radiology 2004; 232: 535-543

23 Rajaram S, Swift AJ, Capener D et al. Diagnostic accuracy of contrast-enhanced MR angiography and unenhanced proton MR imaging compared with CT pulmonary angiography in chronic thromboembolic pulmonary hypertension. Eur Radiol 2012; 22: 310-317
24 Ley S, Ley-Zaporozhan J, Pitton MB et al. Diagnostic performance of state-of-the-art imaging techniques for morphological assessment of vascular abnormalities in patients with chronic thromboembolic pulmonary hypertension (CTEPH). Eur Radiol 2012; 22: 607-616

25 Reichelt A, Hoeper MM, Galanski $M$ et al. Chronic thromboembolic pulmonary hypertension: evaluation with 64-detetcor row CT versus digital subtraction angiography. Eur J Radiol 2009; 71: 49-54

26 Sugiura T, Tanabe N, Matsuura Y et al. Role of 320-slice CT imaging in the diagnostic workup of patients with chronic thromboembolic pulmonary hypertension. Chest 2013; 143: 1070-1077

27 He J, Fang W, Lu B et al. Diagnosis of chronic thromboembolic pulmonary hypertension: comparison of ventilation/perfusion scanning and multidetector computed tomography pulmonary angiography with pulmonary angiography. Nucl Med Commun 2012; 33: 459-463

28 Tanabe N, Sugiara T, Tatsumi K. Recent progress in the diagnosis and management of chronic thromboembolic pulmonary hypertension. Respiratory Investigation 2013; 51: 134-146

29 Tunariu N, Gibbs SJR, Win Z et al. Ventilation-perfusion scintigraphy is more sensitive than multidetector CTPA in detecting chronic thromboembolic pulmonary disease as a treatable cause of pulmonary hypertension. J Nucl Med 2007; 48: 680-684

30 Kreitner KF, Kunz RP, Ley $S$ et al. Chronic thromboembolic pulmonary hypertension - assessment by magnetic resonance imaging. Eur Radiol 2007; 17: 605-609

31 Nikolaou K, Schoenberg SO, Attenberger U et al. Pulmonary arterial hypertension: diagnosis with fast perfusion MR imaging and high-spatial-resolution MR angiography - preliminary experience. Radiology 2005; 236: 694-703

32 Ley S, Kreitner KF, Morgenstern I et al. Bronchopulmonary shunts in patients with chronic thromboembolic pulmonary hypertension: evaluation with helical CT and MR imaging. Am J Roentgenol Amer J Roentgenol 2002; 179: 1209-1215

33 Remy-Jardin M, Duhamel A, Deken V et al. Systemic collateral supply in patients with chronic thromboembolic and primary pulmonary hypertension: assessment with multi-detector row helical CT angiography. Radiology 2005; 235: 274-281

34 Ley S, Grünig E, Kiely D et al. Computed tomography and magnetic resonance imaging of pulmonary hypertension: pulmonary vessels and right ventricle. J Magn Reson Imaging 2010; 32: 1313-1324

35 Ley S, Fink C, Ley-Zaporozhan J et al. Value of high spatial and high temporal resolution magnetic resonance angiography for differentiation between idiopathic and thromboembolic pulmonary hypertension: initial results. Eur Radiol 2005; 15: 2256-2263

36 Kreitner KF, Ley-Zaporozhan J, Ley S et al. Value of MR perfusion compared with MR angiography for assessment of small and large vessel disease in patients with chronic thromboembolic pulmonary hypertension. RSNA 2010, http://abstract.rsna.org/index.cfm

37 Rajaram S, Swift AJ, Telfer A et al. 3D contrast-enhanced lung perfusion MRI is an effective screening tool for chronic thromboembolic pulmonary hypertension: results from the ASPIRE Registry. Thorax 2013; 68: 677-678

38 Hoey ETD, Mirsadraee S, Pepke-Zaba J et al. Dual energy CT angiography for assessment of regional pulmonary perfusion in patients with chronic thromboembolic pulmonary hypertension: initial experience. Am J Roentgenol Amer J Roentgenol 2011; 196: 524-532

39 Renard B, Remy-Martin M, Santangelo T et al. Dual-energy CT angiography of chronic thromboembolic disease: can it help recognize links between the severity of pulmonary arterial obstruction and perfusion defects? Eur J Radiol 2011; 79: 467 - 472

40 Dournes $G$, Verdier D, Montaudon $M$ et al. Dual-energy CT perfusion and angiography on chronic thromboembolic pulmonary hypertension: diagnostik accuracy and concordance with radionuclide scinitigraphy. Eur Radiol 2014; 24: $42-51$

41 Meinel FG, Graef A. Thierfelder KM et al. Automated quantification of pulmonary perfused blood volume by dual-energy CTPA in chronic thromboembolic pulmonary hypertension. Fortschr Roentgenstr 2014; 186: 151 - 156

42 Becker HC, Johnson T. Cardiac CT for the assessment of chest pain: imaging techniques and clinical results. Eur J Radiol 2012; 81: 3675-3679

43 Ayaram D, Bellolio F, Murad MH et al. Triple rule-out computed tomographic angiography for chest pain: a diagnostic systematic review and meta-analysis. Acad Emerg Med 2013; 20: 861 -871

44 Bostel T, Stork K, Schneider J et al. Die EKG-getriggerte 128-Schicht-CT bei der Abklärung von Patienten mit chronisch-thromboembolischer 
pulmonaler Hypertonie (CTEPH): Erste Erfahrungen. Fortschr Roentgenstr 2010; 182: S193

45 D'Arminini AM, Zanotti G, Ghio $S$ et al. Reverse right ventricular remodeling after pulmonary endarterectomy. J Thorac Cardiovasc Surg 2007; 133: $162-168$

46 Reesink HJ, Marcus JT, Tulevski II et al. Reverse right ventricular remodeling after pulmonary endarerterectomy in patient with chronic thromboembolic pulmonary hypertension: utility of magnetic resonance imaging to demonstrate restoration of the right ventricle. J Thorac Cardiovasc Surg 2007; 133: 58 - 64

47 Iino M, Dymarkowski S, Chaothawee L et al. Time course of reversed cardiac remodeling after pulmonary endarterectomy in patients with chronic pulmonary throboembolism. Eur Radiol 2008; 18: 792 - 79

48 Mauritz GJ, Vonk-Noordegraf A, Kind T et al. Pulmonary endarterectomy normalizes interventricular dyssynchrony and right ventricular systolic wall stress. J Cardiovasc Magn Reson 2012; 14: 5

49 Kreitner KF. Noninvasive imaging of pulmonary hypertension. Semin Respir Crit Care Med 2014; 35: 99-111

50 Liu M, Ma Z, Guo X et al. Computed tomographic pulmonary angiography in the assessment of severity of chronic thromboembolic pulmonary hypertension and right ventricular dysfunction. Eur J Radiol 2011; 80: e462 - e469

51 Liu M, Ma Z, Guo X et al. Cardiovascular parameters of computed tomographic pulmonary angiography to assess pulmonary vascular resistance in patients with chronic thromboembolic pulmonary hypertension. Int J Cardiol 2013; 164: 295 - 300

52 Garcia-Alvarez A, Fernandez-Friera L, Mirelis JG et al. Non-invesive estimation of pulmonary vascular resistance with cardiac magnetic resonance. Eur Heart J 2011; 32: 2438-2445
53 Swift AJ, Rajaram S, Hurdman J et al. Noninvasive estimation of PA pressure, flow, and resistance with CMR imaging. J Am Coll Cardiol Img 2013; 6: 1036-1047

54 Kreitner KF, Wirth GM, Krummenauer F et al. Non-invasive assessment of pulmonary hemodynamics in patients with chronic thromboembolic pulmonary hypertension (CTEPH) by high temporal resolution phase-contrast MR imaging: correlation with simultaneous invasive pressure recordings. Circ Cardiovasc Imaging 2013; 6: 722 - 729

55 Wijesurija S, Chandratreya L, Medford AR. Chronic pulmonary emboli and radiologic mimics on CT pulmonary angiography. Chest 2013; 143: $1460-1471$

56 Bendel E, Maleszewski JJ, Araoz P. Imaging sarcomas of the great vessels and heart. Semin Ultrasound CT MRI 2011; 32: 377-404

57 Rajaram S, Swift AJ, Davies C et al. Primary pulmonary artery sarcoma and coexisting chronic thromboemblic pulmonary hypertension. Am J Respir Crit Care Med 2013; 188: e7-e8

58 Toledano K, Guralnik L, Lorber A et al. Pulmonary arteries involvement in Takayasu's arteritis: two cases and literature review. Semin Arthritis Rheum 2011; 41: 461 - 470

59 Bächler P, Pinochet $N$, Sotelo J et al. Assessment of normal flow patterns in the pulmonary circulation by using $4 \mathrm{D}$ magnetic resonance velocity mapping. Magn Reson Imaging 2013; 31: 178-188

60 Reiter G, Reiter U, Kovacs G et al. Magnetic resonance-derived 3-dimensional blood flow patterns in the main pulmonary artery as a marker of pulmonary hypertension and a measure of elevated mean pulmonary arterial pressure. Circ Cardiovasc Imaging 2008; 1: 23-30 